\title{
Performance Analysis of Reheat Steam Temperature Control System of Thermal Power Unit Based on Constrained Predictive Control
}

\author{
Xiaoli Li $\mathbb{D}^{1,},{ }^{1,2,3}$ Jian Liu $\mathbb{D}^{1},{ }^{1}$ Kang Wang $\mathbb{D},{ }^{1}$ Fuqiang Wang, ${ }^{4}$ and Yang $\mathrm{Li}^{5}$ \\ ${ }^{1}$ Faculty of Information Technology, Beijing University of Technology, Beijing 100124, China \\ ${ }^{2}$ Beijing Key Laboratory of Computational Intelligence and Intelligent System, Engineering Research Center of Digital Community, \\ Ministry of Education, Beijing 100124, China \\ ${ }^{3}$ Beijing Advanced Innovation Center for Future Internet Technology, Beijing University of Technology, Beijing 100124, China \\ ${ }^{4}$ Technology Research Center, Shenhua Guohua Electric Power Research Institute Corporation, Beijing 100025, China \\ ${ }^{5}$ School of International Studies, Communication University of China, Beijing 100024, China
}

Correspondence should be addressed to Xiaoli Li; lixiaolibjut@bjut.edu.cn

Received 17 April 2019; Revised 28 June 2019; Accepted 8 July 2019; Published 5 August 2019

Guest Editor: Xiaoqing Bai

Copyright (C) 2019 Xiaoli Li et al. This is an open access article distributed under the Creative Commons Attribution License, which permits unrestricted use, distribution, and reproduction in any medium, provided the original work is properly cited.

\begin{abstract}
The reheat steam temperature control system of thermal power unit is a complex control object with time-varying parameters and large delay. In order to achieve precise control of reheat steam temperature, the performance of the reheat temperature control system is analyzed according to the data that are obtained based on the constrained predictive control algorithm. Firstly, the process and mathematical model of reheat steam temperature control system are introduced. Then the principle of constrained predictive control algorithm is analyzed. Finally, the steady-state values of control quantities of reheat steam temperature control system under different conditions are given by MATLAB simulation, and, by analyzing the steady-state values and steady-state time of the input and output of the system, the reference values and the regulating law of the control quantities and the specific constraint range of the control quantities of the system are given, which can provide reference data and theoretical basis for the field adjustment of the reheat steam temperature control system in power plant and improve the safety and effectiveness of the system.
\end{abstract}

\section{Introduction}

In recent years, China's electric power industry has developed rapidly. Ultra-supercritical thermal power unit, which has the characteristics of nonlinear, uncertain parameters and time-variation, has become the main unit in coal-fired power generation industry. Thus higher requirements for automatic control of coal-fired power plants are put forward. At the same time, China's clean energy industry has made great progress, and a variety of clean energy sources have entered the electricity market, which has a certain impact on the traditional coal-fired plants. In order to improve the market competitiveness of coal-fired plants, it is necessary to improve the efficiency of unit continuously. Increasing the pressure and temperature of steam is an effective means to improve competitiveness, but, due to the design requirement of the unit's infrastructure design and the limitation of metal material of boiler, the upgrading and transformation of operating parameters of unit require a large amount of investment of funds. Therefore, it is very important to improve the control effect of steam temperature on the existing basis.

In thermal power unit, reheat steam temperature is an important parameter that affects the economic value of unit. The reheat steam temperature control system is a complex object with the characteristics of large inertia and hysteresis, and the dynamic characteristics of the system are different during the load variation of generator unit, which make the control of reheat steam temperature extremely difficult. If the reheat steam temperature is too high, it may increase the corrosion of the metal material of pipeline and the heating surface of the boiler through which the steam flows, so 
that the service life of unit may be reduced. If the steam temperature is too low, the humidity of steam will be very high, which not only makes the last turbine blades more vulnerable to damage, but also reduces the thermal efficiency of unit. The large variation of reheat steam temperature will also cause unit fatigue and reduce the service life of unit. Therefore, understanding the regulating law of the control quantities and the constraint range of the control quantities of the reheat steam temperature control system can not only ensure the safety of thermal equipment, but also have important significance to the stability of reheat steam temperature.

In order to improve the control effect of steam temperature, a large number of scholars have adopted a variety of advanced control strategies to study it. A new cascade feedback control system with load feed-forward of reheat steam temperature is proposed in [1]. Single-Neuron Selfadaptive PSD algorithm controller applied to outer loop and double-degree PID controller is applied to inner loop, which achieves good control effect. In [2], based on the characteristics of superheated steam temperature of a boiler, a new cascade control system is designed. The main regulator adopts multimodel observer control, and the secondary controller adopts weighted synthesizing proportional control. The system integrates the characteristics of the multimodel control with those of the state variable control with observer. The results show that the control system has strong robustness. In [3], an adaptive predictive control algorithm is designed for the reference model, and two compensators are introduced; one is two-order compensator for process; the other one is time delay compensator for the reference model. The algorithm has been applied in a 200MW peak regulating drum boiler for reheating temperature process, and high control accuracy is obtained. As the superheated steam temperature has large inertia, time-delay, and nonlinearity and its dynamic characteristics change with the operating conditions, a self-tuning PID controller based on fuzzy-RBF neural networks is presented for its control in [4], which has the advantages of traditional PID control, neutral networks control, and fuzzy control and optimizes online PID parameters. In [5], a new intelligent control algorithm of cloud models is proposed. The variant dimension cloud model intelligent controller, which contains a one-dimension cloud model controller to eliminate steadystate error, is designed, and it is used for superheated steam temperature control of a supercritical once-through $600 \mathrm{MW}$ boiler. In [6], a multimodel internal mode control strategy is proposed, and it has been successfully applied to a 1024 $\mathrm{t} / \mathrm{h}$ supercritical pressure boiler. Performance studies show that the control strategy ensures that the superheated steam temperature stays within the desired range for both steady and varying loads. In [7], dynamic matrix control (DMC) is applied in controlling steam temperatures of a large-scale once-through boiler-turbine system. Online optimization is performed for the DMC using the step response model. The simulation results show satisfactory performance of the proposed DMC technique. Aiming at the characteristics of large inertia, large time delay, and nonlinearity of Reheater Temperature Control System, a hybrid optimization algorithm
(MPSO-RBF) for radial basis function (RBF) neural network based on modified particle swarm optimization (MPSO) is presented in [8]. The results have proved that MPSORBF method has good performance index. In [9], a scheme combining neural network identification technology and adaptive inverse control technology is proposed for the control of boiler superheated steam temperature in fossilfired power plant. The identified inverse model is preset as the controller and connected in series with the controlled object to form an adaptive inverse control system. In $[10,11]$, active disturbance rejection control (ADRC) is applied in the control of superheated steam temperature. Comparing with PID algorithm, the method achieved an excellent performance. In [12], a nonlinear control strategy for steam power plants is proposed. The strategy decomposes the overall plant into three separate subsystems and applies decoupling with dead time compensation for each one of them. The simulation results show that the method has good performance and robustness. When the superheated steam temperature is controlled by adjusting the cooling water, the nonlinear characteristics of the valve are caused by the flow rate. In [13], by collecting the valve input and output data and fitting the valve flow characteristic curve, a valve opening degree compensator based on the polynomial fitting method was designed. The simulation results show that the method can overcome the nonlinear problem caused by valve flow characteristics. In [14], a system of automatic control over the temperature of superheated steam for the boiler with three-tier steam cooling system is considered. A regulating algorithm rests on a cascade control method with the temperature error correction based on a force signal. The force signal is a speed of steam temperature change after the condensate injection. The simulation results show the effectiveness of the method. Besides, based on robust $\mathrm{H} \infty \mathrm{c}$ control method, the reheat steam temperature control system of boiler is studied in [15]. In [16], according to the characteristics of reheat steam temperature, a hybrid optimization method based on Biogeography-Based Optimization $(\mathrm{BBO})$ algorithm is proposed to optimize the traditional PID controller. It turns out that the optimized PID controller has better tracking ability and better anti-internal and external interference performance in reheat steam control system.

Aiming at the difficulty of reheat steam temperature control, model predictive control is a useful control method. It can deal with multivariable, constrained, and time-delay problems effectively and has good dynamic control performance. Model predictive control (MPC) [17-20] was proposed in the 1980s. It has been improved and developed continuously in recent years and has been widely used in many industrial fields such as robots [21-24]. The control mechanism of MPC is that, at each sampling time, according to the current measurement information, an open-loop optimization problem in finite time domain is solved online, and the first element of the control sequence is acted on the controlled object. At the next sampling time, the above process is repeated; that is, the optimization problem is refreshed and resolved with new measurements. In addition, in the actual industrial control process, the physical quantity 


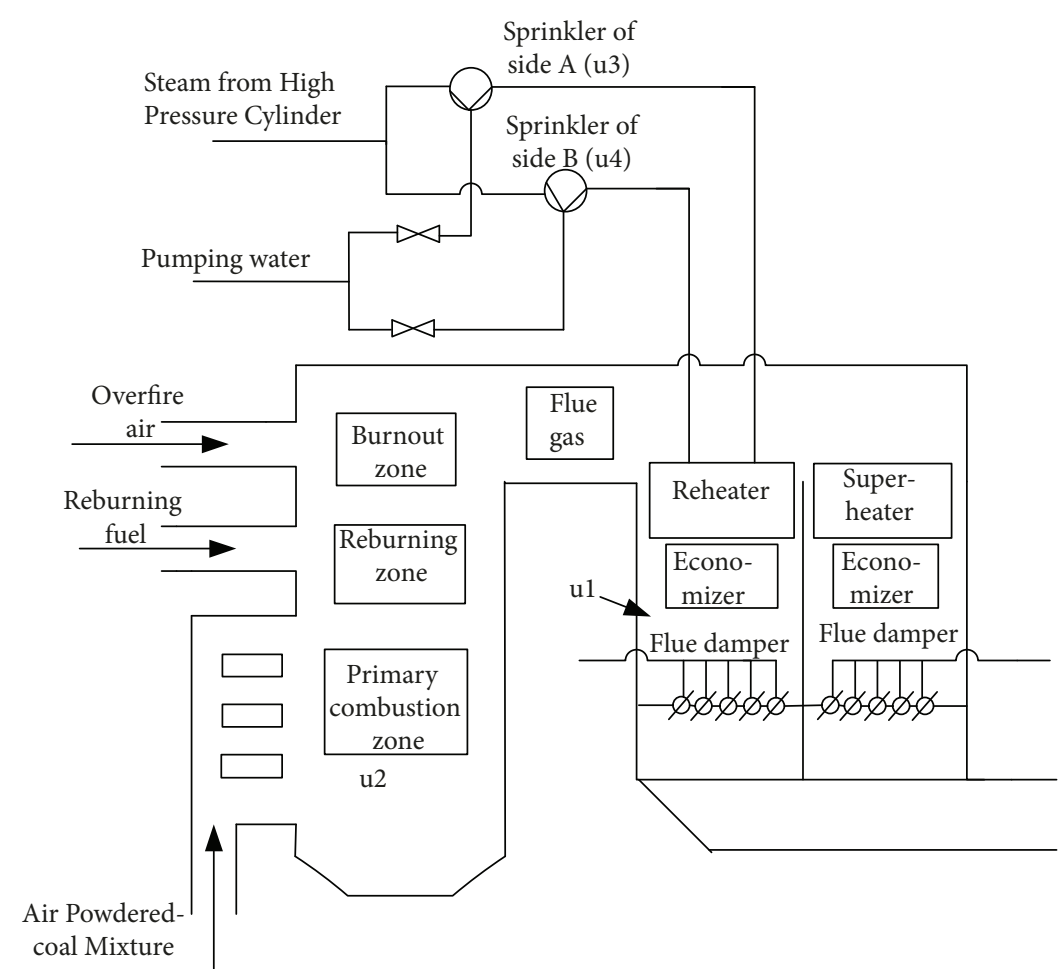

FIgURE 1: The process diagram of reheat steam temperature control system.

of the system can only be taken in a certain range, such that the opening range of the valve dampers in the unit of thermal power plant can only be taken from $0 \%$ to $100 \%$. Executing agencies are not allowed to change too much to prevent damage to them. Therefore, in actual control process, the control input and output must be constrained according to the actual requirement, so that their values can be kept within a certain range. Considering the above factors, the reheat steam temperature control system of $660 \mathrm{MW}$ Ultrasupercritical Once-through Boiler in a power plant is taken as the research object in this paper. And the control process of reheat steam temperature in coal-fired power plant is studied and analyzed by using constrained predictive control algorithm. Through the simulation results, the regulation law and the restriction range of system inputs during the reheat steam temperature system regulation are obtained, which provides theoretical and data support for field regulation. In this way, we can improve the safety and efficiency of reheat steam temperature control and the quality of reheat steam temperature control of ultra-supercritical coal-fired units.

The paper is organized as follows. In Section 2, the technological principle and mathematical model of reheat steam temperature control system are formulated. Then the principle of constrained predictive control algorithm is analyzed in Section 3. In Section 4, we apply constrained predictive control to reheat steam temperature control system and carry out MATLAB simulation. And, by analyzing the simulation results, the input regulation law and appropriate constraint range of system inputs are given. Finally, conclusions are given in Section 5.

\section{The Technological Principle and Mathematical Model of Reheat Steam Temperature Control System}

2.1. The Technological Principle of Reheat Steam Temperature Control System. At present, in order to improve the operation efficiency of large-scale thermal power unit, the steam which has finished the work in the high-pressure cylinder is reheated generally. The process of steam reheating involves three steps. At first, the steam discharged from high pressure cylinder is resent back to the boiler for heating. Then the reheat steam is heated to a certain temperature. Finally, the reheat steam is sent to the middle- and low-pressure cylinders for work.

There are many ways to regulate reheat steam temperature. The commonly used methods include adjusting flue gas damper opening, swinging burner swing angle, and spraying water to reduce temperature. The process diagram of reheat steam temperature control system is shown in Figure 1. In the control process of steam temperature, reheat steam pipe is generally divided into side $\mathrm{A}$ and side $\mathrm{B}$. The burner and the flue gas baffle act on the reheat steam temperature of both sides at the same time. The sprinkler that is installed on the A side and the B side of the reheater can only control the reheat steam temperature of the $A$ side and the $B$ side, respectively. When reheat steam temperature is controlled by flue gas damper, the tail flue of the boiler is divided into two parallel flues. Low temperature reheater is arranged in the main flue, low temperature superheater is arranged in the bypass flue, and economizer is arranged behind them. 
Temperature regulating damper is installed under economizer. By changing the opening of two flue dampers, the ratio of flue gas that flows through cryogenic reheater and cryogenic superheater is changed, so as to control the temperature of reheat steam. Specifically, when the opening of the flue gas damper increases, the reheat steam temperature increases; otherwise the reheat steam temperature decreases. The way of adjusting the swing angle of the burner is to change the up and down inclination angle of the swing burner nozzle, which will adjust the position of the high temperature flame center in the furnace, so as to change the flue gas temperature at the outlet of the furnace and control the reheat steam temperature. Similar to the flue gas damper, the reheat steam temperature increases with the increase of burner swing angle; otherwise the reheat steam temperature decreases. In case of emergency, sprinklers on both sides of reheater can spray water to cool down.

In general, adjusting flue gas damper opening and burner swing angle is the main control means in the control process of reheat steam temperature system. The performance of burner swing angle regulation and flue gas damper regulation is stable, and heat shock is small, so the two control methods have higher thermal economy. Although spray desuperheating has a rapid effect on reheat steam temperature control, it will reduce the thermal efficiency of the unit, so it is not the main method of regulation. Usually only in the process of unit start-up and shutdown, or in the case of accident, spray desuperheating is used as an auxiliary emergency means. Besides, in the normal operation of the unit, small amount of cooling water can be used intermittently, or it can be combined with other temperature regulation methods as a fine-tuning method of reheat steam.

\subsection{The Mathematical Model of Reheat Steam Temperature} Control System. From the above analysis, we can learn that the ideal control method for the reheat steam temperature should be to use the burner swing angle and the flue gas damper to adjust the reheat steam temperature roughly and use the method of water spraying to reduce the temperature to achieve fine adjustment. As an emergency safety measure, the sprinkler valve should be kept as small as possible. At the same time, the variance of burner swing angle and flue gas damper opening must be limited to a certain range.

According to the requirements of reheat temperature control process, the mathematical model [25] of reheat steam temperature control system for $660 \mathrm{MW}$ ultra-supercritical once-through boiler in a power plant is established:

$$
\left[\begin{array}{l}
y_{1} \\
y_{2}
\end{array}\right]=\left[\begin{array}{cccc}
G_{11} & G_{12} & G_{13} & 0 \\
G_{21} & G_{22} & 0 & G_{24}
\end{array}\right] \times\left[\begin{array}{l}
u_{1} \\
u_{2} \\
u_{3} \\
u_{4}
\end{array}\right] .
$$

where $u_{1}, u_{2}, u_{3}, u_{4}$ are the control quantities of the system and $y_{1}, y_{2}$ are the output of the system. It should be noted that the model is established based on the input variance and output variance of reheat steam temperature control system. For example, in model (1), $y_{1}$ is the variance of the reheat steam temperature on the A side of reheater, rather than the actual reheat steam temperature. If the initial temperature of reheat steam is $580^{\circ} \mathrm{C}$ and the expected temperature is $590^{\circ} \mathrm{C}$, then $y_{1}$ is the change of the initial temperature, that is, $10^{\circ} \mathrm{C}$. Similarly, $y_{2}$ is the variance of reheat steam temperature on the $\mathrm{B}$ side of reheater, $u_{1}$ is the variance of the flue gas damper opening, $u_{2}$ is the variance of the burner swing angle, $u_{3}$ is the variance of the sprinkler valve opening on the A side of reheater, and $u_{4}$ is the variance of the sprinkler valve opening on the $\mathrm{B}$ side of reheater.

The transfer functions of burner swing angle-reheat steam temperature, flue gas damper-reheat steam temperature, and spray desuperheating-reheat steam temperature can be described by the mode of first-order inertia plus pure delay. The expression of the transfer functions is as follows:

$$
G(s)=\frac{K}{T s+1} \exp (-\tau s),
$$

where $K$ is the gain, $T$ is the first-order inertia time, and $\tau$ is the delay time. The transfer function form of $G_{11}, G_{12}$, $G_{13}, G_{21}, G_{22}, G_{24}$ in model (1) is determined by (2).

\section{Theoretical Analysis of Constrained Predictive Control [26]}

The theoretical analysis of predictive control algorithm is usually based on the state space equation of the system model. Therefore, the transfer function model of the research object in this paper needs to be transformed into the state space model. The transformation method can be easily found in many data [27], so it is no longer detailed.

The state space incremental model of the linear discrete time system is considered as follows:

$$
\begin{aligned}
\Delta x(k+1) & =A \Delta x+B_{u} \Delta u(k)+B_{d} \Delta d(k), \\
y_{c}(k) & =C_{c} \Delta x(k)+y_{c}(k-1), \\
y_{b}(k) & =C_{b} \Delta x(k)+y_{b}(k-1),
\end{aligned}
$$

where

$$
\begin{aligned}
& \Delta x(k)=x(k)-x(k-1), \\
& \Delta u(k)=u(k)-u(k-1), \\
& \Delta d(k)=d(k)-d(k-1) .
\end{aligned}
$$

In the model ((3a), (3b), and (3c)), $\Delta x(k) \in \mathbb{R}^{n_{x}}$ is the state increment; $\Delta u(k) \in \mathbb{R}^{n_{u}}$ is the increment of control input; $\Delta d(k) \in \mathbb{R}^{n_{d}}$ is the increment of measurable external interference; $y_{c}(k) \in \mathbb{R}^{n_{c}}$ is the controlled output; $y_{b}(k) \in$ $\mathbb{R}^{n_{b}}$ is the constrained output; $A, B_{u}, B_{d}, C_{c}, C_{b}$ is the system matrix of the corresponding dimension.

The control objective is to make the controlled output $y_{c}$ track the given reference input $r$. At the same time, the control 
quantity, control increment, and output of the system satisfy the following control constraints and output constraints:

$$
\begin{gathered}
u_{\text {min }}(k) \leq u(k) \leq u_{\max }(k), \quad \forall k \geq 0, \\
\Delta u_{\min }(k) \leq \Delta u(k) \leq \Delta u_{\max }(k), \quad \forall k \geq 0, \\
y_{\min }(k) \leq y_{b}(k) \leq y_{\max }(k) . \quad \forall k \geq 0,
\end{gathered}
$$

At $k$ time, the measured value of state is $x(k)$. According to the basic principle of predictive control, the optimization problem of constrained MPC is described as follows.

\section{Question 1}

$$
\min _{\Delta U(k)} J(x(k), \Delta U(k))
$$

satisfies system dynamics $(i=0,1, \cdots, p)$ and the following time-domain constraints ((8a), (8b), and $(8 c))$ :

$$
\begin{aligned}
& \Delta x(k+i+1 \mid k)=A \Delta x(k+i \mid k)+B_{u} \Delta u(k+i) \\
& +B_{d} \Delta d(k+i), \\
& \Delta x(k \mid k)=\Delta x(k) \\
& y_{c}(k+i \mid k)=C_{c} \Delta x(k+i \mid k) \\
& +y_{c}(k+i-1 \mid k), \quad i \geq 1 \text {, } \\
& y_{c}(k \mid k)=y_{c}(k) \text {, } \\
& y_{b}(k+i \mid k)=C_{b} \Delta x(k+i \mid k) \\
& +y_{c}(k+i-1 \mid k), \quad i \geq 1, \\
& y_{b}(k \mid k)=y_{b}(k) \text {, } \\
& u_{\min }(k+i) \leq u(k+i) \leq u_{\max }(k+i) \text {, } \\
& i=0,1, \cdots, m-1 \text {, } \\
& \Delta u_{\min }(k+i) \leq \Delta u(k+i) \leq \Delta u_{\max }(k+i), \\
& i=0,1, \cdots, m-1 \text {, } \\
& y_{\min }(k+i) \leq y_{b}(k+i) \leq y_{\max }(k+i) . \\
& i=0,1, \cdots, p \text {, }
\end{aligned}
$$

where

$$
\begin{aligned}
J(x(k), \Delta U(k))= & \left\|\Gamma_{y}\left(Y_{p, c}(k+1 \mid k)-R(k+1)\right)\right\|^{2} \\
& +\left\|\Gamma_{u} \Delta U(k)\right\|^{2} .
\end{aligned}
$$

In the above optimization problems, $\Gamma_{y}$ and $\Gamma_{u}$ are weighted matrices, and they are given as follows:

$$
\begin{aligned}
& \Gamma_{y}=\operatorname{diag}\left\{\Gamma_{y, 1}, \Gamma_{y, 2}, \cdots \Gamma_{y, p}\right\}_{p \times p}, \\
& \Gamma_{u}=\operatorname{diag}\left\{\Gamma_{u, 1}, \Gamma_{u, 2}, \cdots \Gamma_{u, m}\right\}_{m \times m},
\end{aligned}
$$

$R(k+1)$ is a reference sequence of control output, and it is given as

$$
R(k+1)=\left[\begin{array}{c}
r(k+1) \\
r(k+2) \\
\vdots \\
r(k+p)
\end{array}\right]_{p \times 1}
$$

$\Delta U(k)$ is a sequence of control quantity. As an independent variable for constrained optimization problems, it is defined as

$$
\Delta U(k) \stackrel{\operatorname{def}}{=}\left[\begin{array}{c}
\Delta u(k) \\
\Delta u(k+1) \\
\vdots \\
\Delta u(k+m-1)
\end{array}\right]_{m \times 1},
$$

$Y_{p, c}(k+1 \mid k)$ is the $\mathrm{p}$ step control output based on model $((3 a),(3 b)$, and $(3 c))$ prediction at $k$ time, and it is defined as

$$
Y_{p, c}(k+1 \mid k) \stackrel{\text { def }}{=}\left[\begin{array}{c}
y_{c}(k+1 \mid k) \\
y_{c}(k+2 \mid k) \\
\vdots \\
y_{c}(k+p \mid k)
\end{array}\right]_{p \times 1} .
$$

Specifically, the controlled output $y_{c}(k+i \mid k)$ and constrained output $y_{b}(k+i \mid k)$ of predictive control are calculated by equation ((7a), (7b), (7c), (7d), (7e), and (7f)), where $(7 \mathrm{~b}),(7 \mathrm{~d})$, and $(7 \mathrm{f})$ indicate that the measured states are the initial condition for predicting the future dynamics of the system. If the states are not all measurable, the estimated states are used as the initial conditions for predicting the future dynamics of the system.

$Y_{p, c}(k+1 \mid k)$ can be calculated by the equation

$$
\begin{aligned}
Y_{p, c}(k+1 \mid k)= & S_{x} \Delta x(k)+I y_{c}(k)+S_{u} \Delta U(k) \\
& +S_{d} \Delta d(k),
\end{aligned}
$$

where

$$
S_{x}=\left[\begin{array}{c}
C_{c} A \\
C_{c} A^{2}+C_{c} A \\
\vdots \\
\sum_{i=1}^{p} C_{c} A^{i}
\end{array}\right]_{p \times 1},
$$$$
I=\left[\begin{array}{c}
I_{n_{c} \times n_{c}} \\
I_{n_{c} \times n_{c}} \\
\vdots \\
I_{n_{c} \times n_{c}}
\end{array}\right]_{p \times 1}
$$ 
$S_{d}=\left[\begin{array}{c}C_{c} B_{d} \\ C_{c} A B_{d}+C_{c} B_{d} \\ \vdots \\ \sum_{i=1}^{p} C_{c} A^{i-1} B_{d}\end{array}\right]_{p \times 1}$

$S_{u}$

$=\left[\begin{array}{ccccc}C_{c} B_{u} & 0 & 0 & \cdots & 0 \\ \sum_{i=1}^{2} C_{c} A^{i-1} B_{u} & C_{c} B_{u} & 0 & \cdots & 0 \\ \vdots & \vdots & \vdots & & \vdots \\ \sum_{i=1}^{m} C_{c} A^{i-1} B_{u} & \sum_{i=1}^{m-1} C_{c} A^{i-1} B_{u} & \cdots & \cdots & C_{c} B_{u} \\ \vdots & \vdots & \vdots & & \vdots \\ \sum_{i=1}^{p} C_{c} A^{i-1} B_{u} & \sum_{i=1}^{p-1} C_{c} A^{i-1} B_{u} & \cdots & \cdots & \sum_{i=1}^{p-m+1} C_{c} A^{i-1} B_{u}\end{array}\right]_{p \times m}$

The constrained optimization problem is a quadratic programming $(\mathrm{QP})$ problem, so we transform it into a $\mathrm{QP}$ description. The specific transformation process is detailed in [15].

The constraint MPC optimization Question 1 is converted into the following QP problem description:

$$
\begin{gathered}
\min _{\Delta U(k)} \Delta U(k)^{T} H \Delta U(k)-G(k+1 \mid k)^{T} \Delta U(k) \\
\text { satisfies } C_{u} \Delta U(k) \geq b(k+1 \mid k) .
\end{gathered}
$$

The QP problem ((16a) and (16b)) has a solution to any weighting matrix $\Gamma_{y} \geq 0, \Gamma_{u} \geq 0$, which is denoted as $\Delta U^{*}(k)$. Obviously, $\Delta U^{*}(k)$ is a function that is related to the measured value $x(k)$, the control horizon $m$, and the prediction horizon $p$. According to the basic principle of predictive control, the first step of the obtained open-loop control sequence will be applied to the controlled system. At the next sampling time, the constrained optimization question 1, that is, QP problem ((16a) and (16b)), will be refreshed with the new measured value and solved again. Therefore, the closed-loop control law of constrained MPC is defined as

$$
\Delta u(k)=\left[\begin{array}{llll}
I_{n_{u}} \times I_{n_{u}} & 0 & \cdots & 0
\end{array}\right] \Delta U^{*}(k) .
$$

\section{Performance Analysis of Reheat Steam Temperature Control System with Variable Load}

4.1. Simulation Results. The transfer functions [25] of spray desuperheating (valve opening), reheat steam temperature, burner swing angle, reheat steam temperature and flue gas damper, and reheat steam temperature of a 660MW ultrasupercritical once-through boiler under 400MW, 500MW, and 600MW load are shown in Tables 1, 2, and 3.

According to the mathematical model in Tables 1, 2 and 3 , we simulate the control effect of reheat steam temperature
TABLE 1: The model of flue gas damper-reheat steam temperature under $400 \mathrm{MW}, 500 \mathrm{MW}$, and $600 \mathrm{MW}$.

\begin{tabular}{lll}
\hline Load & \multicolumn{1}{c}{$G_{11}$} & $G_{21}$ \\
\hline & & \\
$400 \mathrm{MW}$ & $\frac{0.34}{284.5 s+1} e^{-251 s}$ & $\frac{0.31}{261.3 s+1} e^{-250 s}$ \\
$500 \mathrm{MW}$ & $\frac{0.69}{244.2 s+1} e^{-170 s}$ & $\frac{0.67}{214.3 s+1} e^{-152 s}$ \\
$600 \mathrm{MW}$ & $\frac{0.85}{210.1 s+1} e^{-121 s}$ & $\frac{0.81}{201.2 s+1} e^{-121 s}$ \\
\hline
\end{tabular}

TABLE 2: The model of burner swing angle-reheat steam temperature under $400 \mathrm{MW}, 500 \mathrm{MW}$, and $600 \mathrm{MW}$.

\begin{tabular}{lll}
\hline Load & \multicolumn{1}{c}{$G_{12}$} & \multicolumn{1}{c}{$G_{22}$} \\
\hline $400 \mathrm{MW}$ & $\frac{1}{345.6 s+1} e^{-300 s}$ & $\frac{1.01}{324.1 s+1} e^{-300 s}$ \\
$500 \mathrm{MW}$ & $\frac{1.18}{375.1 s+1} e^{-251 s}$ & $\frac{1.275}{384.2 s+1} e^{-260 s}$ \\
$600 \mathrm{MW}$ & $\frac{1.36}{397.3 s+1} e^{-161 s}$ & $\frac{1.445}{289.5 s+1} e^{-153 s}$ \\
\hline
\end{tabular}

system of boiler based on constraint predictive control algorithm when the loads of generator unit are 400MW, 500MW, and $600 \mathrm{MW}$, respectively. The initial temperature of reheat steam is set to $580^{\circ} \mathrm{C}$ and the expected output temperature of reheat steam is set to $590^{\circ} \mathrm{C}$; that is, the reference input is $r=10$. The sampling period is 10 seconds. The prediction horizon is $\mathrm{p}=100$, and the control horizon is $\mathrm{m}=3$. The output error weighting matrix of quadratic performance index is ywt $=[]$, and control quantity weighting matrix of quadratic performance index is uwt $=\left[\begin{array}{llll}1 & 1 & 1 & 1\end{array}\right]$.

In order to make comparison and analysis, the constraints of $u_{j}$ are set to $0 \sim 8,0 \sim 10,0 \sim 12$, and $0 \sim 15$, respectively, where $j=1,2,3,4$. Note that if we want to rise the reheat steam temperature, $u_{1}, u_{2}$ should be greater than or equal to 0 and $u_{3}, u_{4}$ should be close to or equal to 0 . Therefore, the constraints of $u_{j}$ should start from 0 . The unit of $u_{1}, u_{3}, u_{4}$ is $\%$. The unit of $u_{2}$ is degree.

When the load of generator unit is $400 \mathrm{MW}, u_{j} \in[0,15]$, $\Delta u_{j}=0.5$, the simulation results of reheat steam temperature control system are shown in Figures 2 and 3.

From Figures 2 and 3, we can see that the steady state values of $u_{1}, u_{2}, u_{3}, u_{4}$ are $13.94,5.62,0.26$, and 0 , respectively, and the time that is required for the input and output to reach the steady state is about 120 sampling periods, that is, 1200 s. Similarly, we can obtain the steady state time of the $u_{j}$ and $y_{1,2}$ and the steady state values of $u_{j}$ under different loads and different input constraints, and they are shown in Tables 4, 5,6 , and 7 . According to the data that is obtained from the simulation, we can analyze the control performance of the reheat steam temperature control system.

Since the dynamic characteristics of reheat steam temperature control system are different during the change of generators load, that is, the model parameters of reheat steam temperature control system are changing with the change of generator load, so the models of reheat steam temperature control system under one or several loads can only provide the system input under the one or several loads at the site, 
TABLE 3: The model of spray desuperheating-reheat steam temperature under $400 \mathrm{MW}, 500 \mathrm{MW}$, and $600 \mathrm{MW}$.

\begin{tabular}{llr}
\hline Load & $G_{13}$ & \multicolumn{1}{c}{$G_{24}$} \\
\hline $400 \mathrm{MW}$ & $\frac{-1.4}{85 s+1} e^{-40 s}$ & $\frac{-1.39}{82 s+1} e^{-39 s}$ \\
$500 \mathrm{MW}$ & $\frac{-1.11}{41 s+1} e^{-35 s}$ & $\frac{-1.02}{40 s+1} e^{-34 s}$ \\
$600 \mathrm{MW}$ & $\frac{-0.81}{34 s+1} e^{-26 s}$ & $\frac{-0.79}{31 s+1} e^{-24 s}$ \\
\hline
\end{tabular}

TABLE 4: Steady-state values of $u_{j}$ when $u_{j} \in[0,15]$.

\begin{tabular}{|c|c|c|c|c|c|c|c|c|c|c|c|c|}
\hline \multirow{2}{*}{$\frac{u_{j} \in[0,15]}{\Delta u_{j}}$} & \multicolumn{4}{|c|}{$400 \mathrm{MW}$} & \multicolumn{4}{|c|}{$500 \mathrm{MW}$} & \multicolumn{4}{|c|}{$600 \mathrm{MW}$} \\
\hline & 0.5 & 1 & 1.5 & 2 & 0.5 & 1 & 1.5 & 2 & 0.5 & 1 & 1.5 & 2 \\
\hline Steady-state time of $y_{1,2}$ & 120 & 100 & 90 & 85 & 95 & 87 & 85 & 80 & 60 & 55 & 50 & 45 \\
\hline Steady-state time of $u_{j}$ & 120 & 100 & 90 & 85 & 95 & 87 & 85 & 80 & 60 & 55 & 50 & 45 \\
\hline Steady-state value of $u_{1}$ & 13.94 & 13.2 & 12.63 & 12.12 & 12.62 & 12.78 & 12.61 & 12.44 & 10.63 & 10.89 & 10.56 & 10.20 \\
\hline Steady-state value of $u_{2}$ & 5.62 & 5.84 & 6.02 & 6.18 & 1.21 & 1.13 & 1.22 & 1.34 & 0.96 & 0.82 & 1.00 & 1.20 \\
\hline Steady-state value of $u_{3}$ & 0.26 & 0.24 & 0.23 & 0.22 & 0.12 & 0.13 & 0.12 & 0.11 & 0.42 & 0.45 & 0.42 & 0.38 \\
\hline Steady-state value of $u_{4}$ & 0 & 0 & 0 & 0 & 0 & 0 & 0 & 0 & 0 & 0 & 0 & 0 \\
\hline
\end{tabular}

TABLE 5: Steady-state values of $u_{j}$ when $u_{j} \in[0,12]$.

\begin{tabular}{|c|c|c|c|c|c|c|c|c|c|c|c|c|}
\hline \multirow{2}{*}{$\begin{array}{l}u_{j} \in[0,12] \\
\Delta u_{j}\end{array}$} & \multicolumn{4}{|c|}{$400 \mathrm{MW}$} & \multicolumn{4}{|c|}{$500 \mathrm{MW}$} & \multicolumn{4}{|c|}{$600 \mathrm{MW}$} \\
\hline & 0.5 & 1 & 1.5 & 2 & 0.5 & 1 & 1.5 & 2 & 0.5 & 1 & 1.5 & 2 \\
\hline Steady-state time of $y_{1,2}$ & 110 & 100 & 95 & 90 & 105 & 100 & 98 & 95 & 60 & 55 & 55 & 55 \\
\hline Steady-state time of $u_{j}$ & 110 & 100 & 95 & 90 & 105 & 100 & 98 & 95 & 60 & 55 & 55 & 55 \\
\hline Steady-state value of $u_{1}$ & 11.16 & 10.51 & 9.98 & 9.55 & 11.12 & 10.94 & 10.79 & 10.68 & 10.10 & 9.81 & 9.40 & 9.05 \\
\hline Steady-state value of $u_{2}$ & 6.48 & 6.67 & 6.84 & 6.97 & 2.00 & 2.09 & 2.17 & 2.23 & 1.26 & 1.42 & 1.65 & 1.85 \\
\hline Steady-state value of $u_{3}$ & 0.19 & 0.18 & 0.17 & 0.16 & 0.03 & 0.02 & 0.01 & 0 & 0.37 & 0.33 & 0.29 & 0.25 \\
\hline Steady-state value of $u_{4}$ & 0 & 0 & 0 & 0 & 0 & 0 & 0 & 0 & 0 & 0 & 0 & 0 \\
\hline
\end{tabular}

TABLE 6: Steady-state values of $u_{j}$ when $u_{j} \in[0,10]$.

\begin{tabular}{|c|c|c|c|c|c|c|c|c|c|c|c|c|}
\hline \multirow{2}{*}{$\begin{array}{l}\frac{u_{j} \in[0,10]}{\Delta u_{j}} \\
\end{array}$} & \multicolumn{4}{|c|}{$400 \mathrm{MW}$} & \multicolumn{4}{|c|}{$500 \mathrm{MW}$} & \multicolumn{4}{|c|}{$600 \mathrm{MW}$} \\
\hline & 0.5 & 1 & 1.5 & 2 & 0.5 & 1 & 1.5 & 2 & 0.5 & 1 & 1.5 & 2 \\
\hline Steady-state time of $y_{1,2}$ & 115 & 105 & 100 & 95 & 110 & 100 & 95 & 90 & 105 & 95 & 90 & 80 \\
\hline Steady-state time of $u_{j}$ & 115 & 105 & 100 & 95 & 110 & 100 & 95 & 90 & 105 & 95 & 90 & 80 \\
\hline Steady-state value of $u_{1}$ & 9.25 & 8.65 & 8.18 & 8.05 & 9.73 & 9.59 & 9.46 & 9.35 & 9.09 & 8.71 & 8.33 & 8.03 \\
\hline Steady-state value of $u_{2}$ & 7.06 & 7.25 & 7.39 & 7.43 & 2.78 & 2.87 & 2.92 & 3.01 & 1.82 & 2.04 & 2.25 & 2.42 \\
\hline Steady-state value of $u_{3}$ & 0.15 & 0.13 & 0.12 & 0.11 & 0 & 0 & 0 & 0 & 0.26 & 0.22 & 0.18 & 0.14 \\
\hline Steady-state value of $u_{4}$ & 0 & 0 & 0 & 0 & 0.07 & 0.08 & 0.01 & 0.01 & 0 & 0 & 0 & 0 \\
\hline
\end{tabular}

TABLE 7: Steady-state values of $u_{j}$ when $u_{j} \in[0,8]$.

\begin{tabular}{|c|c|c|c|c|c|c|c|c|c|c|c|c|}
\hline \multirow{2}{*}{$\frac{u_{j} \in[0,8]}{\Delta u_{j}}$} & \multicolumn{4}{|c|}{$400 \mathrm{MW}$} & \multicolumn{4}{|c|}{$500 \mathrm{MW}$} & \multicolumn{4}{|c|}{$600 \mathrm{MW}$} \\
\hline & 0.5 & 1 & 1.5 & 2 & 0.5 & 1 & 1.5 & 2 & 0.5 & 1 & 1.5 & 2 \\
\hline Steady-state time of $y_{1,2}$ & 130 & 130 & 130 & 130 & 120 & 105 & 103 & 100 & 108 & 100 & 98 & 95 \\
\hline Steady-state time of $u_{j}$ & 130 & 130 & 130 & 130 & 120 & 105 & 103 & 100 & 108 & 100 & 98 & 95 \\
\hline Steady-state value of $u_{1}$ & 7.57 & 7.57 & 7.57 & 7.57 & 7.91 & 7.81 & 7.74 & 7.67 & 7.67 & 7.46 & 7.34 & 7.23 \\
\hline Steady-state value of $u_{2}$ & 7.58 & 7.58 & 7.58 & 7.58 & 3.85 & 3.90 & 3.95 & 3.99 & 2.62 & 2.74 & 2.81 & 2.87 \\
\hline Steady-state value of $u_{3}$ & 0.11 & 0.11 & 0.11 & 0.11 & 0 & 0 & 0 & 0 & 0.10 & 0.08 & 0.07 & 0.06 \\
\hline Steady-state value of $u_{4}$ & 0 & 0 & 0 & 0 & 0.20 & 0.21 & 0.22 & 0.22 & 0 & 0 & 0 & 0 \\
\hline
\end{tabular}




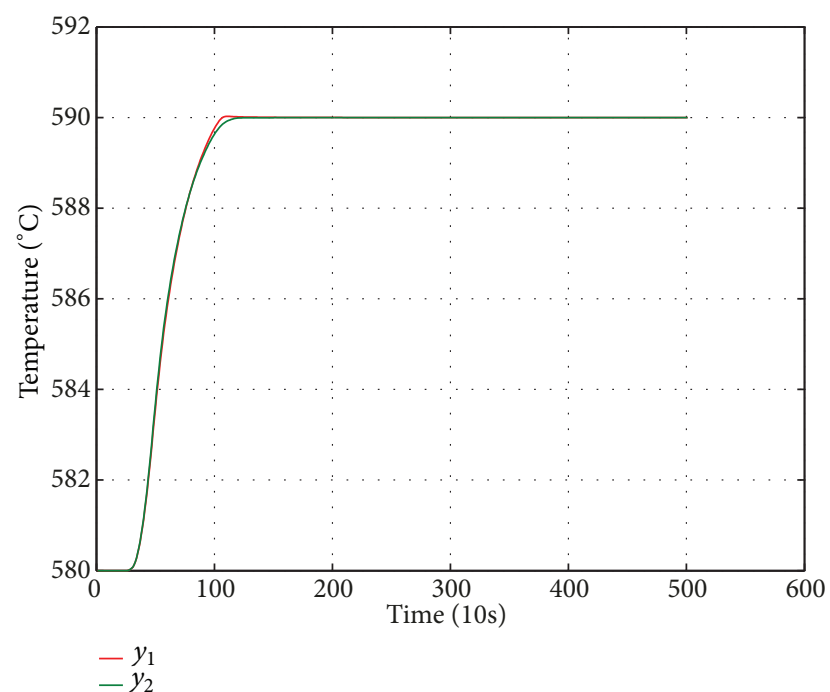

FIGURE 2: The variation curve of reheat steam temperature when the load of generator unit is $400 \mathrm{MW}, u_{j} \in[0,15], \Delta u_{j}=0.5$.

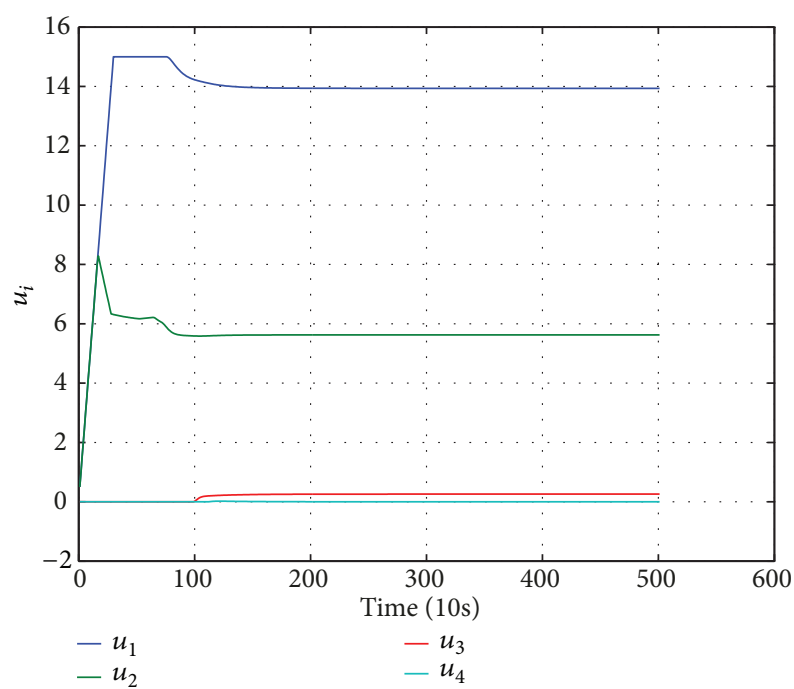

FIGURE 3: The variation curve of system input when the load of generator unit is $400 \mathrm{MW}, u_{j} \in[0,15], \Delta u_{j}=0.5$.

and they cannot provide the basis for the field adjustment of the control system under other loads. Therefore, we need to analyze the input and output of the system based on the existing models under the three loads and get the regulation law of the control quantities, which can provide a theoretical basis for the actual field adjustment.

\subsection{Analysis of Control Quantities of Reheat Steam Tempera-} ture Control System. From the steady-state values of Tables $4,5,6$, and 7 , we can see that $u_{1}$ and $u_{2}$ are relatively large, and they play major roles during the regulation of reheat steam temperature. $u_{3}$ and $u_{4}$ are close to 0 , which means that the opening of the two sprinkler valves remains almost unchanged. It is consistent with the control requirement that spray desuperheating is not as the main regulating method during the regulation of reheat steam temperature.

Control quantities $u_{3}$ and $u_{4}$ do not play a major role during the control process of reheat steam temperature, so we mainly analyze $u_{1}$ and $u_{2}$. Firstly, the change of $u_{1}$ is analyzed. From the Tables $4-7$, it can be seen that when $\Delta u_{j}$ is equal and the constraint of control quantities is invariable, the three steady-state values of $u_{1}$ do not change much under the three loads. That is to say, when the reheat steam temperature rises from $580^{\circ} \mathrm{C}$ to $590^{\circ} \mathrm{C}$ and the load of generator unit is $400 \mathrm{MW}$, the variance of flue gas damper opening is basically the same as that under $500 \mathrm{MW}$ and $600 \mathrm{MW}$ load. Besides, the smaller the constraint range of $u_{1}$ is, the closer the three steady-state values of $u_{1}$ are under the three loads. Thus, although the model parameters of reheat steam temperature control system change with the change of generator load, the adjustment of flue gas damper opening just has little change under different loads. Taking Table 7 as an example, when $u_{j} \in[0,8]$ and $\Delta u_{j}=0.5$, the three steady-state values of $u_{1}$, which are 7.57, 7.91, and 7.67, respectively, are the closest under the three loads. The variation range of $u_{1}$ is between 7.57 and 7.91, and the change is not obvious. Therefore, under any other load, the control quantity $u_{1}$ can take the value from 7.57 to 7.91 .

Next, we analyze the change of $u_{2}$ according to the Tables 4-7. It can be seen that when the $\Delta u_{j}$ is equal and the constraint of control quantities is invariable, $u_{2}$ changes greatly under the three loads. And the higher the generators' load is, the smaller the $u_{2}$ is. Taking Table 5 as an example, when $\Delta u_{j}=0.5$, under $400 \mathrm{MW}, 500 \mathrm{MW}$, and 600MW load, the steady-state values of $u_{2}$ are $6.48,2.00$, and 1.26 , respectively, which means if the reheat steam temperature rises from $580^{\circ} \mathrm{C}$ to $590^{\circ} \mathrm{C}$, the swing angle of the burner needs to be increased by 6.48 under $400 \mathrm{MW}$ load, while the opening of burner swing angle needs to be increased by 2.00 and 1.26 , respectively, under $500 \mathrm{MW}$ and $600 \mathrm{MW}$ loads. It shows that, in the process of regulating the reheat steam temperature control system, with the increase of the load of the generator unit, the adjusting range of burner swing angles should be gradually reduced. Therefore, in the actual field adjustment, the higher the generator load is, the smaller the adjustment range of the burner swing angles should be, so as to avoid damaging thermal equipment caused by excessive reheat steam temperature.

The correctness of the above analysis can also be verified by Simulink simulation. Taking Table 6 as an example, under different loads, we take the steady-state value of $u_{\mathrm{j}}$, respectively, at $\Delta u_{j}=0.5$, as the system input and set the increment of $u_{2}$ to 4 in the Simulink simulation. In this way, we can learn the effect of reheat steam temperature when the adjusting range of burner swing angles is too large. The simulation results are shown in Figures 4, 5, and 6.

From Figure 4, we can see that when the load of the generator unit is $400 \mathrm{MW}$ and the increment of $u_{2}$ is 4 , that is, $u_{2}=7.06+4=11.06$, the reheat steam temperature rises by about $14^{\circ} \mathrm{C}$. It is $4^{\circ} \mathrm{C}$ higher than the desired output, but it still meets the maximum deviation of system output, which is $\pm 5^{\circ} \mathrm{C}$. When the load of the generator unit is $500 \mathrm{MW}$, we can see that the reheat steam temperature rises by about $14.8^{\circ} \mathrm{C}$ 


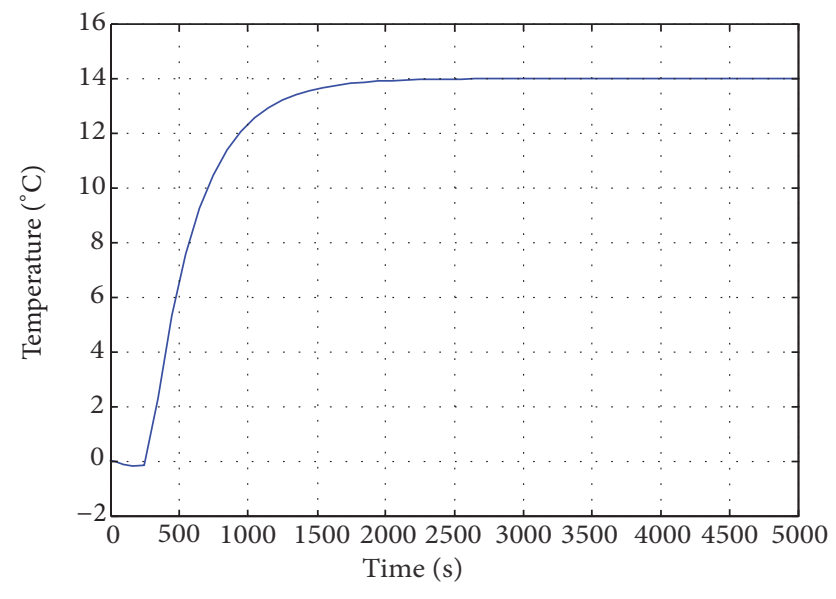

FIGURE 4: The variation curve of $y_{1}$ when the load of generator unit is $400 \mathrm{MW}, u_{j} \in[0,12]$, and the increment of $u_{2}$ is 4 .

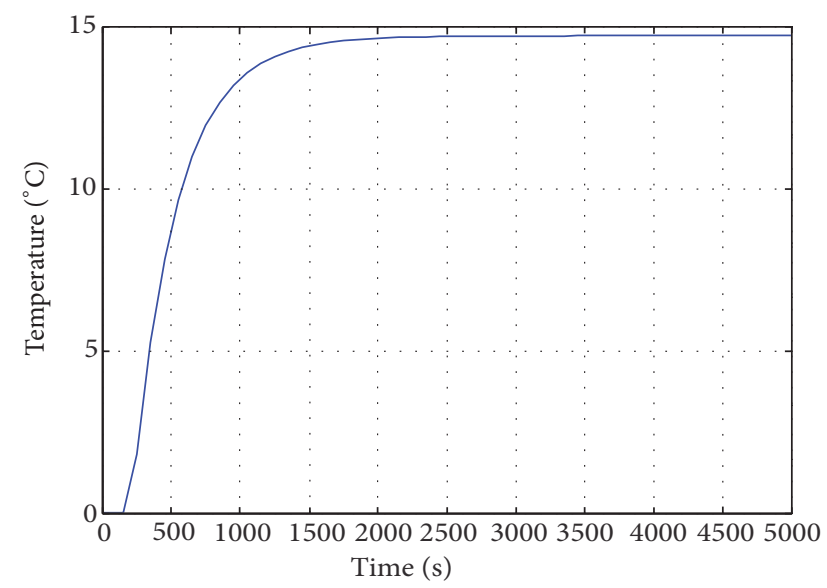

FIGURE 5: The variation curve of $y_{1}$ when the load of generator unit is $500 \mathrm{MW}, u_{j} \in[0,12]$, and the increment of $u_{2}$ is 4 .

from Figure 5, and it is approaching the maximum deviation of output. From Figure 6, we can see that the reheat steam temperature rises by about $15.4^{\circ} \mathrm{C}$ under 600MW load, and it has exceeded the maximum deviation of system output. Thus, in order to ensure the safety of the thermal equipment, the higher the load of the generator unit is, the smaller the adjustment range of the burner swing angles should be.

4.3. Analysis of the Constraint Range of Control Quantities. In this paper, the control quantities $u_{j}$ are the variance of system input. Taking the $u_{1}$ as an example, it is not the actual opening of the flue gas damper, but it is the opening variance of the flue gas damper. If the original opening of the flue gas damper is 50 and $u_{1}=10$, then the actual opening of the flue gas damper is 60 . In the actual process, the opening of the control quantities has a maximum value, so it is necessary to restrict the range of control quantities of the system to ensure that the control quantities do not exceed their maximum value. Next, we analyze the constraints of the control quantities and

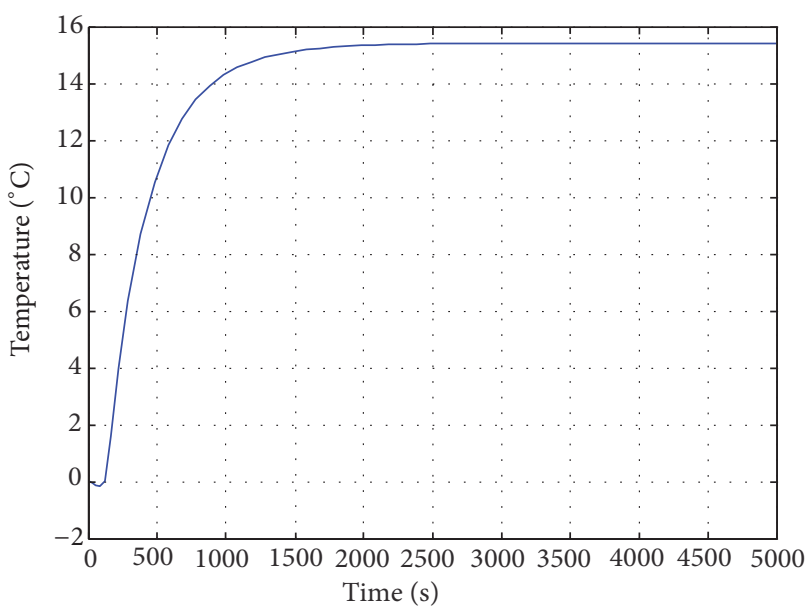

FIGURE 6: The variation curve of $y_{1}$ when the load of generator unit is $600 \mathrm{MW}, u_{j} \in[0,12]$, and the increment of $u_{2}$ is 4 .

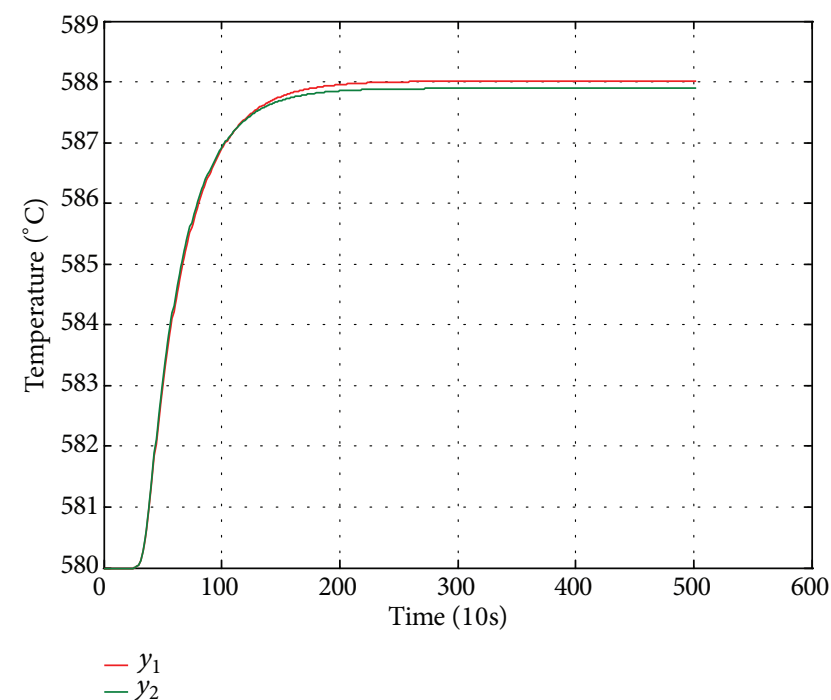

FIGURE 7: The variation curve of reheat steam temperature when the load of generator unit is $400 \mathrm{MW}, u_{j} \in[0,6], \Delta u_{j}=0.5$.

give an appropriate constraint range for reference during field adjustment of reheat temperature control system.

Firstly, the constraint range of the control quantities should not be too small; otherwise the reheat steam temperature cannot reach the desired temperature. Figures 7 and 8 are the simulation results of input and output of the reheat steam temperature system when the generator load is $400 \mathrm{MW}, u_{j} \in$ $[0,6], \Delta u_{j}=0.5$. The initial temperature of reheat steam is $580^{\circ} \mathrm{C}$ and the desired temperature is $590^{\circ} \mathrm{C}$.

It can be easily seen from Figure 7 that when $u_{j}$ is limited to $0 \sim 6$, the steady state values of the reheat steam temperature are about 588.0 and 587.9, which do not reach the desired temperature. From Figure 8, we can be seen that the steadystate values of $u_{1}, u_{2}$ have reached the maximum value of input constraint range, which is 6 , and the steady-state values of $u_{3}, u_{4}$ have almost reached the minimum value of input constraint range, which is 0 . This shows that in the reheat 


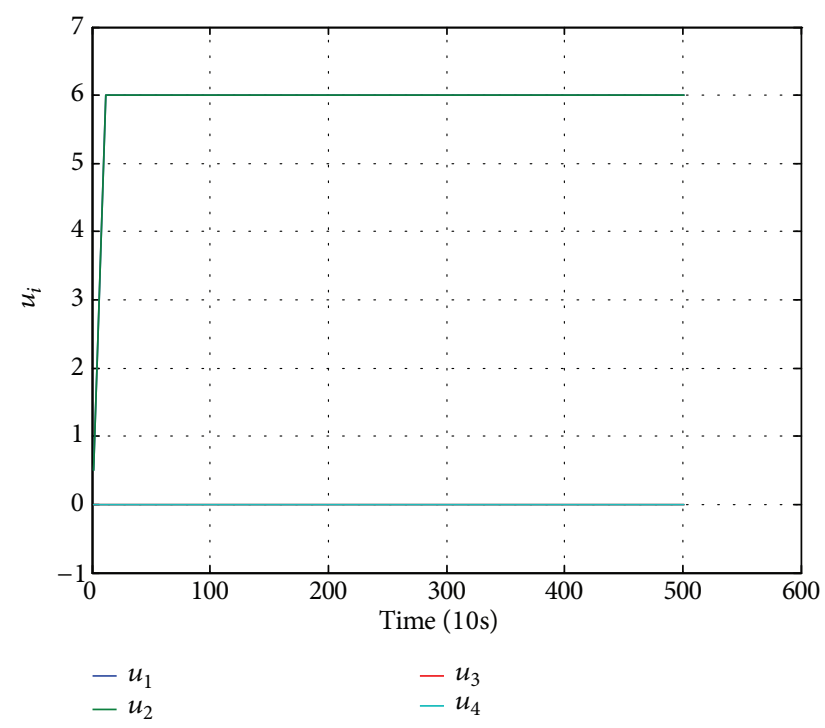

FIgURE 8: The variation curve of system input when the load of generator unit is $400 \mathrm{MW}, u_{j} \in[0,6], \Delta u_{j}=0.5$.

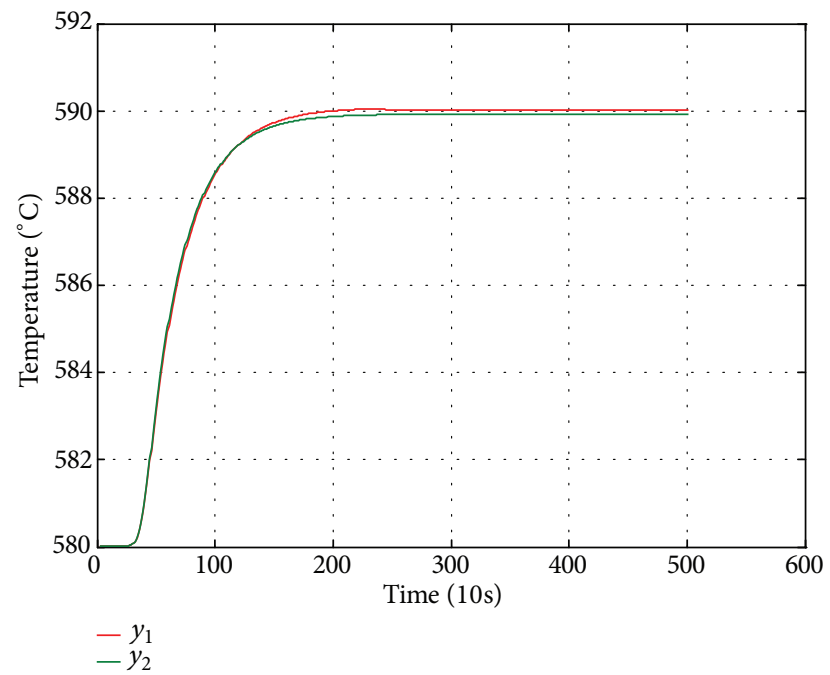

FIGURE 9: The variation curve of reheat steam temperature when the load of generator unit is $400 \mathrm{MW}$ and $u_{j} \in[0,7.5]$.

steam temperature control system, if the constraint range of the control quantities is too small, even if $u_{1}, u_{2}$ reach the upper bound of the constraint range and the $u_{3}, u_{4}$ is close to lower bound, the final reheat steam temperature cannot reach the desired temperature. Therefore, there must be a minimum upper bound for the constraint range of the control quantities. Next, we try to find out the minimum upper bound of the constraint range of the control quantities under 400MW, 500MW, and 600MW loads, respectively, by simulation.

When the load of the generator unit is $400 \mathrm{MW}$ and $u_{j} \in[0,7.5]$, the input and output of the system are shown in Figures 9 and 10. From Figure 10, we can see that the steady-state values of $u_{1}, u_{2}$ have reached the upper bound of input constraint range, which is 7.5 , and the steady-state

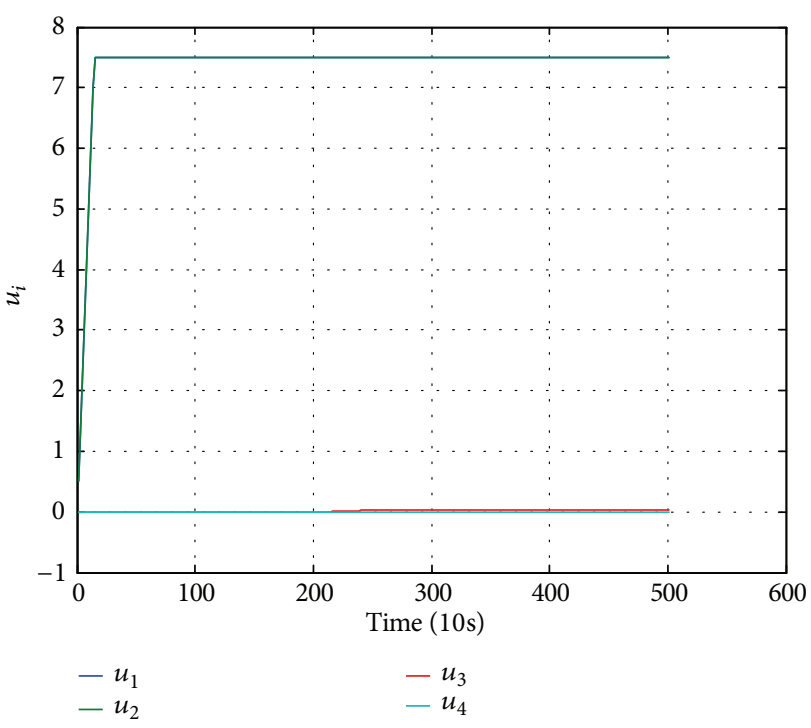

FIgURE 10: The variation curve of system input, when the load of generator unit is $400 \mathrm{MW}, u_{j} \in[0,7.5], \Delta u_{j}=0.5$.

values of $u_{3}, u_{4}$ are 0.03 and 0 , respectively, which have almost reached the lower bound of input constraint range. As can be seen from Figure 9, the steady-state values of $y_{1}, y_{2}$ are 590 and 589.9, respectively, which reach the desired temperature basically. It can be considered that the minimum upper bound of input constraint is about 7.5 under $400 \mathrm{MW}$ load. Similarly, we can get the minimum upper bound of input constraint under $500 \mathrm{MW}$ and $600 \mathrm{MW}$ loads, which are about 5.3 and 4.5, respectively. From the minimum upper bound of the input constraint range under the three loads, we can see that the higher the generator load is, the smaller the minimum upper bound of the input constraint range is. This also shows that, in the actual operation process, with the increase of the generator load, the adjusting range of system inputs should be gradually reduced.

Next, we also make a simple analysis of the maximum upper limit of input constraint range. We can observe the change of system input by simulation when the constraint range of system inputs is too large. When the load of generator unit is $400 \mathrm{MW}, u_{j} \in[0,40], \Delta u_{j}=2$, the variation curve of input and output of the system is shown in Figures 11 and 12. From the two figures, we can see that although the system output can reach the desired value, the steady-state value of $u_{1}$ has reached 29.0 , which means that if the initial opening of $u_{1}$ is greater than 71 , the final value of $u_{1}$ has exceeded the maximum opening it can reach. This is obviously unreasonable. Therefore, the upper limit value of the control quantities constraint range should not be too large; otherwise it may exceed the maximum range of the control quantities opening. What is the maximum upper bound of the control quantities constraint range? If we want to get an exact value, we need a huge amount of data. Since our existing data is limited, we can only analyze it based on the existing data and get a rough analysis result. Compared with the steady-state value of $u_{1}, u_{2}$ in other constraint ranges, when the constraint range of system inputs is $0 \sim 15$, the steady-state value of $u_{1}, u_{2}$ has 
TABLE 8: Reference values of $u_{j}$ and input constraint.

\begin{tabular}{lccc}
\hline$u_{j} \in[0,8], \Delta u_{j}=2$ & $400 \mathrm{MW}$ & $500 \mathrm{MW}$ & $600 \mathrm{MW}$ \\
\hline$u_{1}$ & 7.57 & 7.67 & 7.23 \\
$u_{2}$ & 7.58 & 3.99 & 2.87 \\
$u_{3}$ & 0.11 & 0 & 0.06 \\
$u_{4}$ & 0 & 0.22 & 0 \\
\hline
\end{tabular}

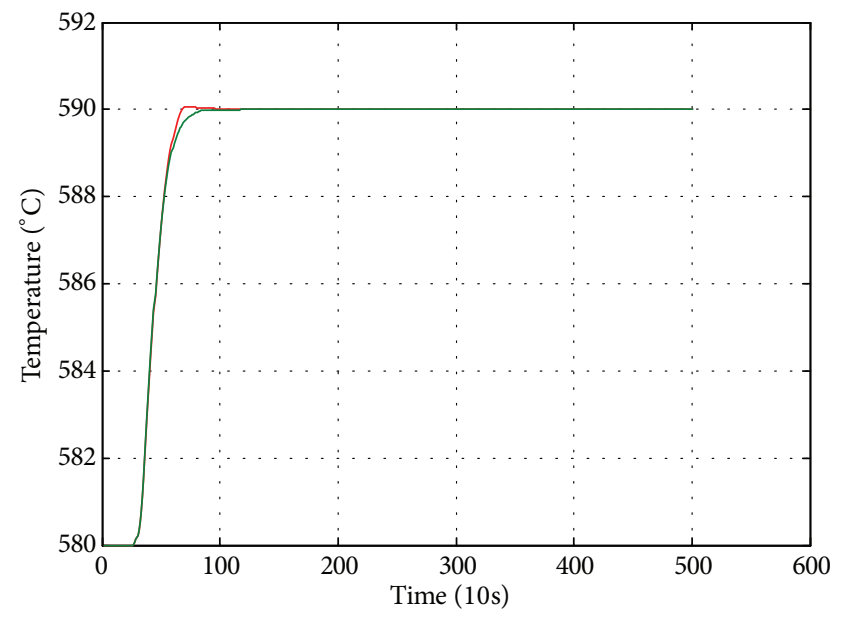

$$
\begin{aligned}
& -y_{1} \\
& -y_{2}
\end{aligned}
$$

FIgURE 11: The variation curve of reheat steam temperature when the load of generator unit is $400 \mathrm{MW}, u_{j} \in[0,40], \Delta u_{j}=2$.

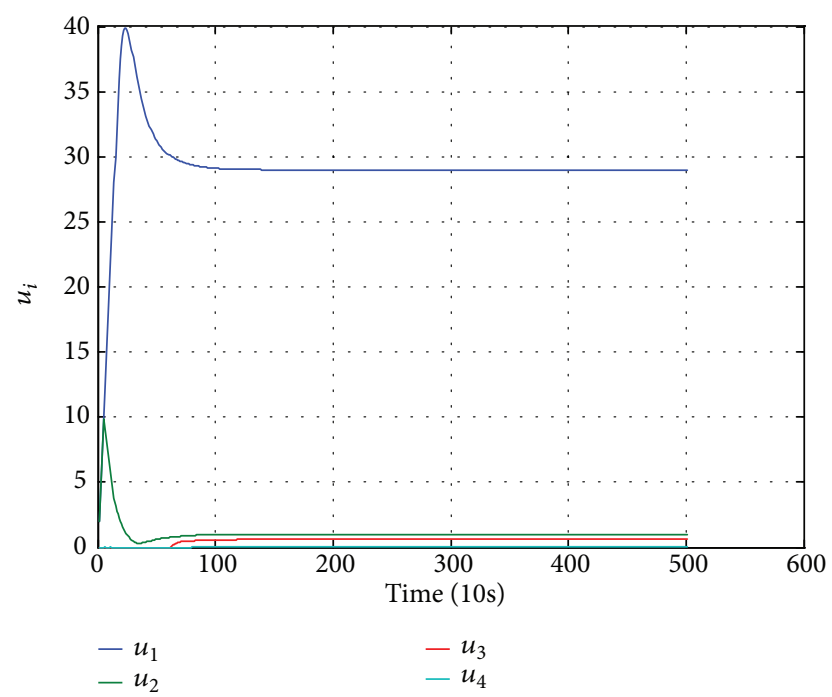

FIGURE 12: The variation curve of system input when the load of generator unit is $400 \mathrm{MW}, u_{j} \in[0,40], \Delta u_{j}=2$.

the largest fluctuation. Therefore, in the existing data, we can roughly consider that the maximum upper bound value of the constraint range of the control quantities is 15 .

From the analysis of Section 4.3 of the control quantities of reheat steam temperature control system, we can learn that, with the increase of the load of the generator unit, the adjusting range of burner swing angles should be gradually reduced, and large adjustment of the control quantities may cause reheat steam temperature being too high and the equipment is damaged, which means that, under different loads, the smaller the fluctuation of $u_{j}$ is, the better the stability and robustness of the system are. By observing and analyzing the data in Tables $4-7$, we can see that when the constraint range of $u_{j}$ is $0 \sim 8$ and $\Delta u_{j}=2$, the fluctuation of steady-state values of $u_{j}$ is the smallest under different loads compared with that in other constraint ranges. In order to provide reference values of $u_{j}$ and input constraint for adjustment of reheat steam temperature system in power plant, the most appropriate input values and input constraint in the existing data are given in Table 8.

\section{Conclusions}

Aiming at the problem of reheat steam temperature control, the reheat steam temperature control system of $660 \mathrm{MW}$ thermal power generator unit is studied based on the constrained predictive control algorithm in this paper. Under the condition of input constraint, steady state value of control quantities and the time that system reaches steady state in different constraint ranges are listed in tabular form. By analyzing the data in the tables, the reference values of system input and input constraint are given. These data and analysis provide reference for field adjustment of reheat steam temperature system in power plant.

\section{Data Availability}

The experimental data used to support the findings of this study are included within the article.

\section{Conflicts of Interest}

The authors declare that there are no conflicts of interest regarding the publication of this paper.

\section{Acknowledgments}

This work is supported in part by the National Natural Science Foundation of China under Grants 61873006, 61473034, and 61673053 and in part by the National Key Research and Development Projects 2018YFC1602704 and 2018YFB1702704 and Beijing Major Science and Technology Special Projects under Grant No. Z181100003118012. 


\section{References}

[1] X. Zhao and Y. Jiao, "Single neuron self-adaptive PSD control and its application in reheat steam temperature control system," Proceedings of the CSEE, vol. 21, pp. 94-97, 2001.

[2] X. Luan, S. Li, and L. Li, "Adaptive control for the superheated steam temperature based on multi-model state observer," IEEE, pp. 978-982, 2004.

[3] H. Lu, J. Sun, and H. Deng, "Design and application of adaptive prediction controller in typical large time delay process in power plant," Journal of Nanjing University of Aeronautics and Astronautics, vol. 38, pp. 151-153, 2006.

[4] W.-Z. Wang, X.-T. Zhao, and Y.-P. Song, "Application of fuzzyRBF-based PID controller in superheated steam temperature control system," Electric Power Automation Equipment, vol. 27, no. 11, pp. 48-50, 2007.

[5] E.-R. Zheng, L.-C. Hui, and X.-M. Wang, "Intelligent control algorithm of cloud models and simulation research of superheated steam temperature control," Journal of System Simulation, vol. 19, no. 1, pp. 98-100, 2007.

[6] Y. Ding, W. Zhao, L. Yuan, and Z. Wu, "Engineering applications of multi-model internal mode control for the superheated steam temperature," Journal of Tsinghua University, vol. 49, no. 11, pp. 1805-1808, 2009.

[7] W. Kim, U.-C. Moon, K. Y. Lee, W.-H. Jung, and S.-H. Kim, "Once-through boiler steam temperature control using dynamic matrix control technique," in Proceedings of the IEEE PES General Meeting, 2010.

[8] B. Xiao, J. Xiao, X. Dong, S. Li, and X. Wang, "Neural network adaptive control for superheated steam temperature based on MPSO-RBF hybrid optimization," Journal of Basic Science and Engineering, vol. 18, no. 4, pp. 705-713, 2010.

[9] W. Wang and J. Wang, "Adaptive inverse control of superheated steam temperature," Electric Power Automation Equipment, vol. 33, no. 9, pp. 54-57, 2013.

[10] G. Liang, W. Li, and Z. Li, "Control of superheated steam temperature in large-capacity generation units based on active disturbance rejection method and distributed control system," Control Engineering Practice, vol. 21, no. 3, pp. 268-285, 2013.

[11] H. Li, T. Pan, Z. Li, S. Ding, S. Guo, and M. K. Ahsan, "Reheated steam temperature control in thermal power plant using integral-linear active disturbance rejection control," in Proceedings of the 2017 11th Asian Control Conference, pp. 2636-2640, 2017.

[12] N. Alamoodi and P. Daoutidis, "Nonlinear control of coal-fired steam power plants," Control Engineering Practice, vol. 60, pp. 63-75, 2017.

[13] L. Wei and P. Xu, "Superheated steam temperature control based on valve nonlinear compensation," in Proceedings of the 37th Chinese Control Conference, pp. 631-635, 2018.

[14] O. V. Kolesnikova, A. D. Tsypkaikina, and R. A. Prosoedov, "Method of automation control of boiler steam temperature," in Proceedings of the 2018 International Russian Automation Conference, 2018.

[15] J. Liu, M. Wang, and Z. Hao, "Boiler reheat steam temperature control based on state variables approach via hotechnology," Journal of Chinese Society of Power Engineering, vol. 29, no. 12, pp. 105-110, 2009.

[16] H. Xue and P. Han, "Hybrid optimization control of reheat steam temperature based on BBO algorithm," in Proceedings of the 7 th International Conference on Intelligent Human-Machine
Systems and Cybernetics, IHMSC 2015, pp. 232-235, China, August 2015.

[17] D. Q. Mayne, J. B. Rawlings, C. V. Rao, and P. O. M. Scokaert, "Constrained model predictive control: stability and optimality," Automatica, vol. 36, no. 6, pp. 789-814, 2000.

[18] D. Q. Mayne, M. M. Seron, and S. V. Raković, "Robust model predictive control of constrained linear systems with bounded disturbances," Automatica, vol. 41, no. 2, pp. 219-224, 2005.

[19] S. Kouro, P. Cortés, R. Vargas, U. Ammann, and J. Rodríguez, "Model predictive control-a simple and powerful method to control power converters," IEEE Transactions on Industrial Electronics, vol. 56, no. 6, pp. 1826-1838, 2009.

[20] D. Q. Mayne, "Model predictive control: recent developments and future promise," Automatica, vol. 50, no. 12, pp. 2967-2986, 2014.

[21] H. Xiao, Z. Li, C. Yang et al., "Robust stabilization of a wheeled mobile robot using model predictive control based on neurodynamics optimization," IEEE Transactions on Industrial Electronics, vol. 64, no. 1, pp. 505-516, 2017.

[22] R. Luo, R. Bourdais, T. J. van den Boom, and B. De Schutter, "Multi-agent model predictive control based on resource allocation coordination for a class of hybrid systems with limited information sharing," Engineering Applications of Artificial Intelligence, vol. 58, pp. 123-133, 2017.

[23] H. Li, W. Yan, and Y. Shi, "Continuous-time model predictive control of under-actuated spacecraft with bounded control torques," Automatica, vol. 75, pp. 144-153, 2017.

[24] J. Ji, A. Khajepour, W. W. Melek, and Y. Huang, "Path planning and tracking for vehicle collision avoidance based on model predictive control with multiconstraints," IEEE Transactions on Vehicular Technology, vol. 66, no. 2, pp. 952-964, 2017.

[25] F. Wang, X. Li, Q. Zhang et al., "Fast calculation method of multivariable control for reheat steam temperature based on Smith control and predictive functional control," Journal of Computer Applications, vol. 35, no. 12, pp. 3597-3601, 2015.

[26] H. Chen, Model Predictive Control, Science Press, China, 2013.

[27] D. Zheng, Linear System Theory, Tsinghua University Press, China, 2002. 


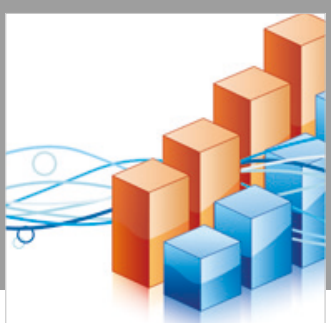

Advances in

Operations Research

\section{-n-m}
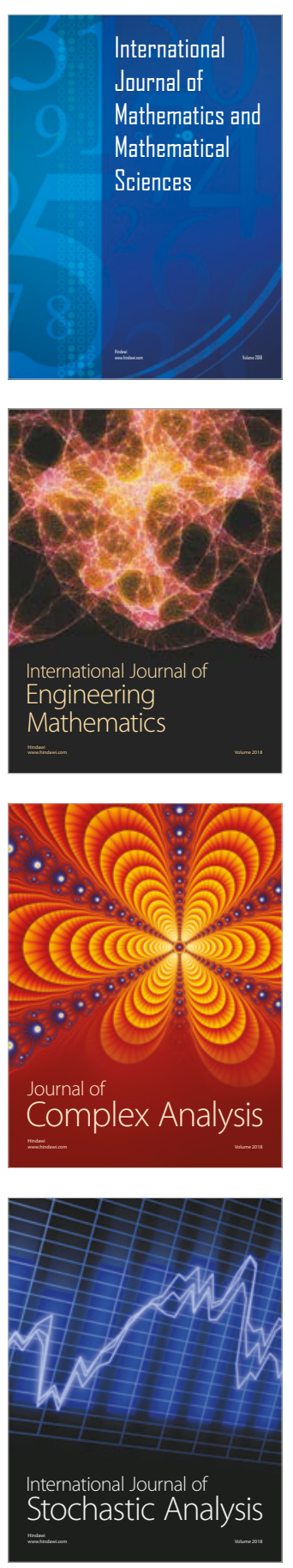
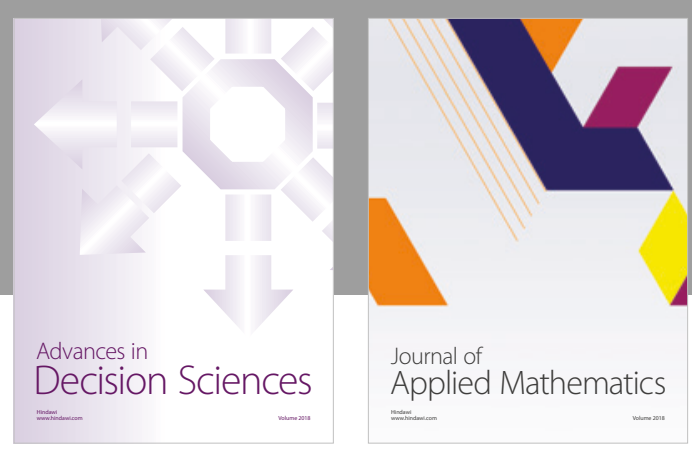

Journal of

Applied Mathematics
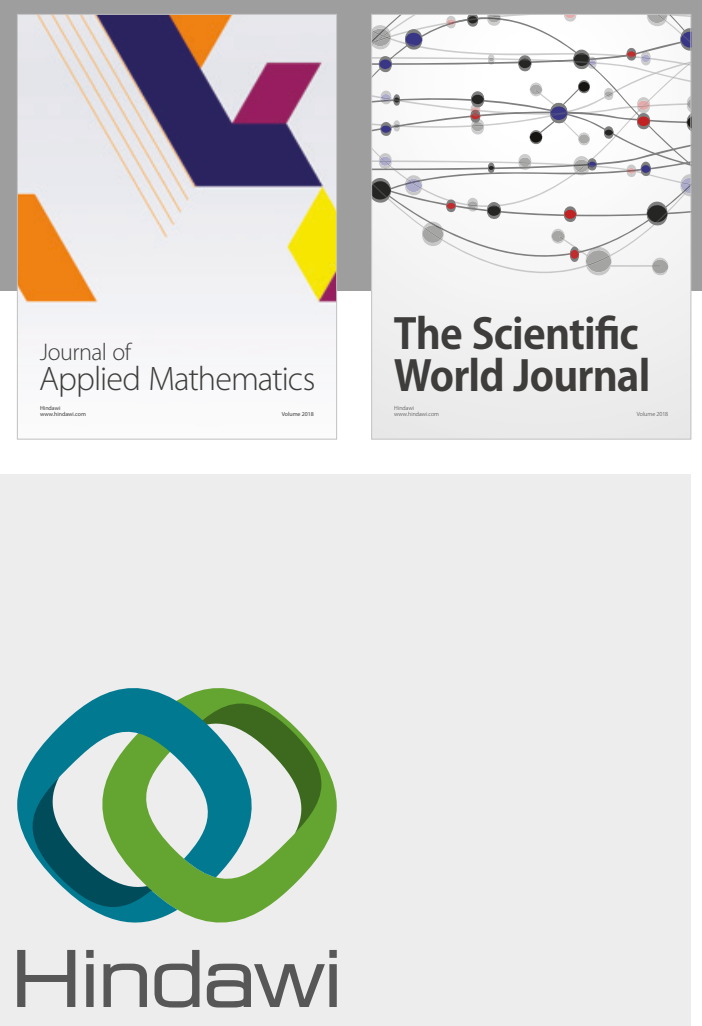

Submit your manuscripts at

www.hindawi.com

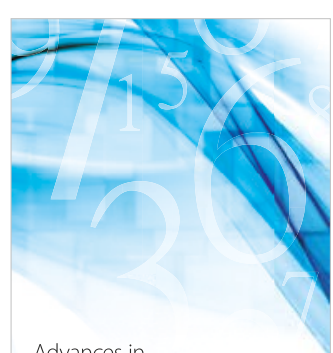

Advances in
Numerical Analysis
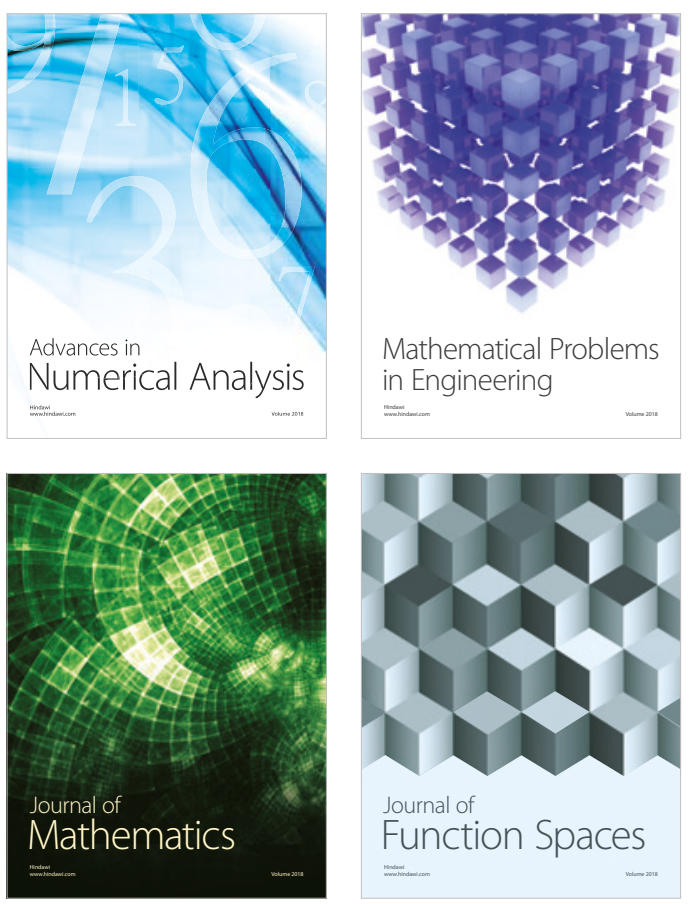

Mathematical Problems in Engineering

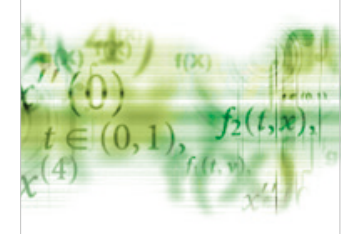

International Journal of

Differential Equations

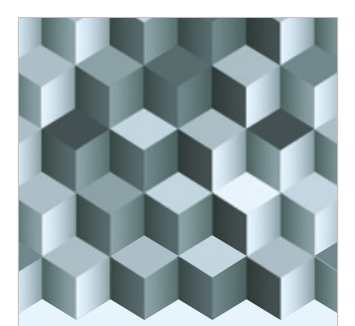

Journal of

Function Spaces
The Scientific

World Journal

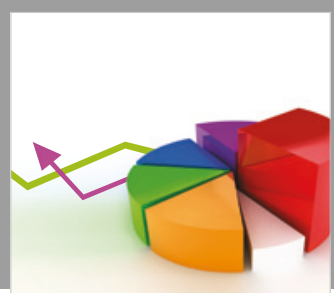

Journal of

Probability and Statistics
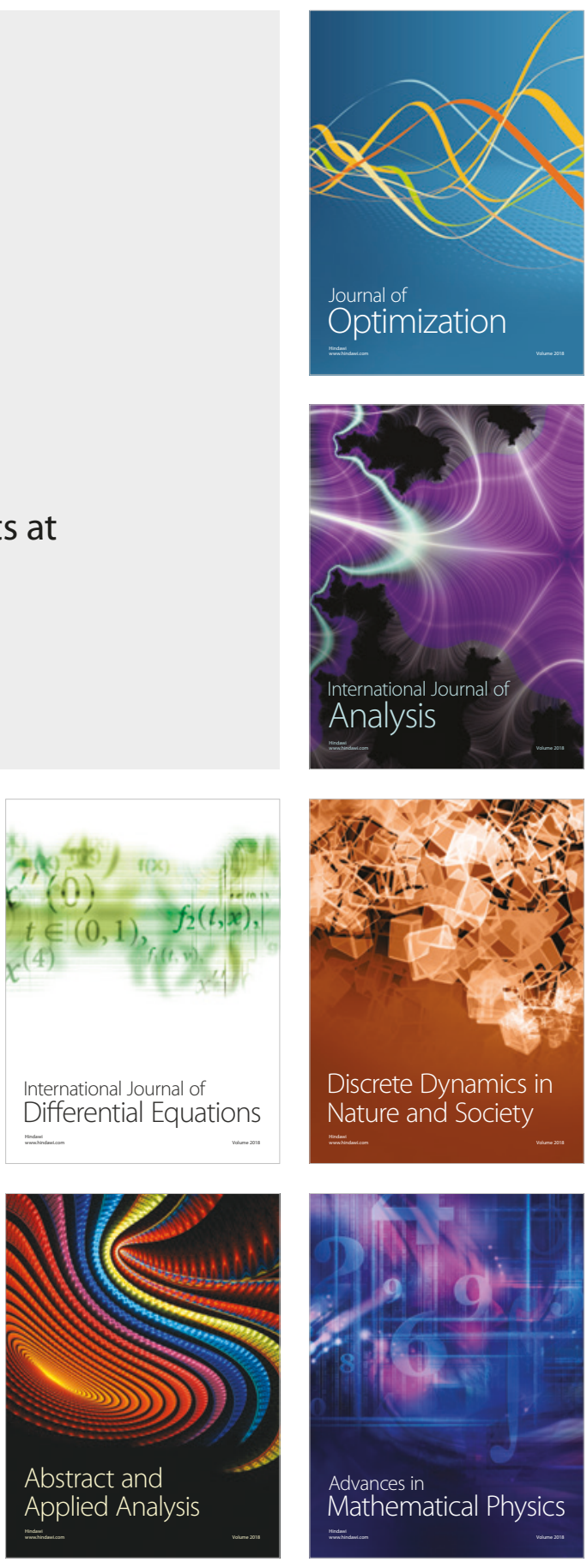